\title{
Simulation of Flow ANd HeAt TRANSFER IN THE TIP REGION OF A BRUSH SEAL
}

\author{
J. W. ChEW and C. GUARDino* \\ Fluids Research Centre, \\ School of Engineering, \\ University of Surrey, \\ Guildford, Surrey GU2 7XH, UK
}

\begin{abstract}
This study considers the flow between the bristle tips and the rotor of an idealized brush seal. CFD results show that the 'air-riding' effect thought by other workers to have occurred in their experiments may be produced by tilting of the bristle tip surface relative to the rotor. This tilting may occur in practice as the rotor to stator clearance increases and the bristles are blown down onto the rotor. CFD solutions are obtained for cases with and without angled tips, assuming either rectangular or hexagonal bristle packing, and both with and without axial flow. Various tip angles and minimum tip-to-rotor clearances are considered, and the trends found are compared with theoretical results for $2 \mathrm{D}$, low Reynolds number flow. The most complete model presented includes heat conduction in the models and heat generation due to contact friction.
\end{abstract}

\section{Nomenclature}

$c \quad$ 'wedge' height (relative to $z=0$ plane)

$D \quad$ viscous drag force acting on rotor $(\mathrm{N})$

$\boldsymbol{e}_{x}, \boldsymbol{e}_{y}, \boldsymbol{e}_{z}$ unit vectors in $\mathrm{x}, \mathrm{y}$ and $\mathrm{z}$ directions

$f_{1}, f_{2}$ maximum and minimum clearances

$f(x)$ clearance

$H \quad$ bristle length included in domain (m)

$l \quad$ projected bristle diameter on the $x-y$ plane

$L \quad$ net lift force acting on bristle (N)

n surface normal

$p \quad$ pressure $(\mathrm{Pa})$

$R \quad$ bristle radius (m), or normal reaction force $(\mathrm{N})$

Re Reynolds number

$Q \quad$ heat source per unit volume $\left(\mathrm{W} / \mathrm{m}^{3}\right)$

$s \quad$ radial distance from front plate to rotor

$S \quad$ cross-sectional surface area $\left(\mathrm{m}^{2}\right)$

* present address CD adapco Group, London Office, 200 Shepherds Bush road, London W6 7NY, UK. 


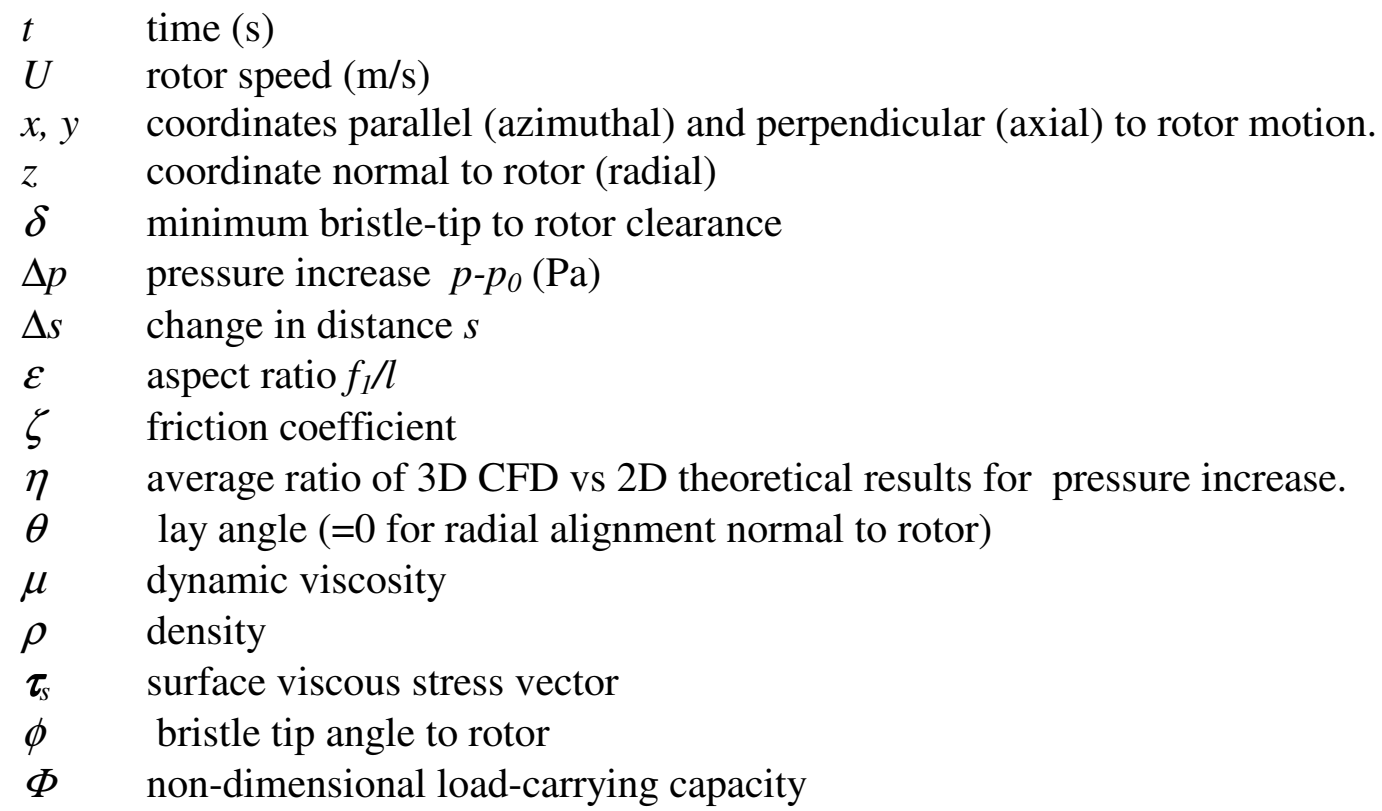

\section{Subscripts}

0 reference (base) conditions

\section{Superscripts}

* Reynolds equation solution

\section{INTRODUCTION}

Advances in sealing technology for gas turbine engines could have significant impact on engine operating costs and reduced fuel consumption. Seals between rotating and stationary components are commonly used in jet engines to control cooling airflows, to prevent ingress of the mainstream gas into the turbine disc cavities, and to prevent oil leakage from the engine bearing chambers. Brush seals have been recognised as a potential replacement for labyrinth seals currently used in turbo-engines. However, despite much experimentation and the fact that brush seals have successfully operated in jet engines, their behaviour is not fully understood. Moreover, advances are still required, especially because of high maintenance costs due to wear which occurs as bristle tips contact the rotating parts.

A schematic of a brush seal is shown in fig. 1. Typically this might comprise a $1 \mathrm{~mm}$ width pack of wire bristles of diameter about $0.1 \mathrm{~mm}$ clamped between an annular front plate (on the high pressure side) and a backing ring. The seal extends circumferentially around a rotating shaft with the inner backing ring radius of order 1 $\mathrm{mm}$ larger than the shaft radius, and the inner front plate radius of order $10 \mathrm{~mm}$ larger than the shaft radius. The bristles are inclined in the orthogonal $(r-\theta)$ plane at a typical 'lay angle' of 45 degrees to the radial direction. Design variables include bristle and backing ring dimensions, bristle materials, pack thickness, lay angle, bristle packing (as influenced by method of manufacture) and degree of interference or clearance fit. Important characteristics of the seal include leakage flow rate, pressure bearing capacity, service life, and tolerance to relative movement of the rotor and stator during operation. 


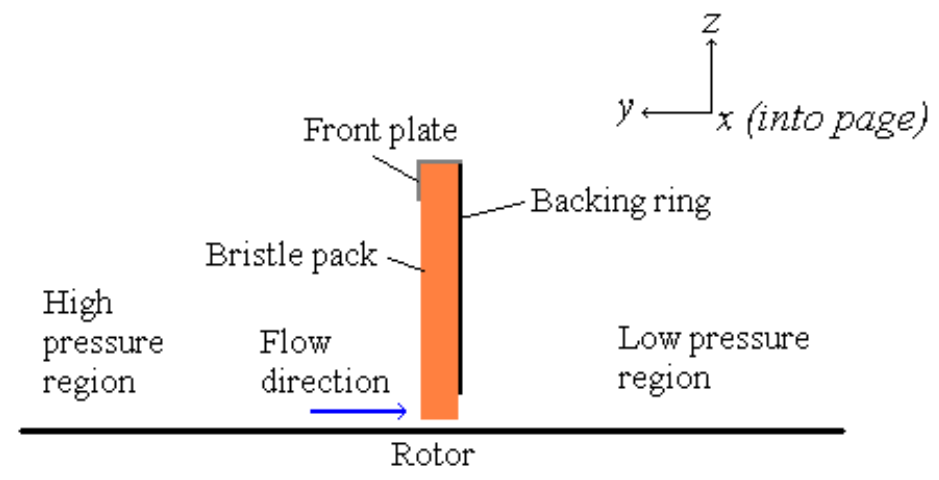

Fig. 1. Schematic of a brush seal.

Previous investigations have established that brush seals offer improved sealing performance compared to existing labyrinth seals. Data including leakage rates, pressure distributions, forces on the rotor and stiffness measurements have been obtained from both CFD and experimental studies (see, for example, Chupp and Holle, 1992, Bayley and Long, 1993, and Chen et al, 1999, 2000). Prediction of the effects of bristle bending has also been carried out by, for example, Hendricks et al (1991), Chew et al (1995) and Aksit and Tichy (1996). The present contribution extends the previous work with a detailed consideration of the flow in the bristle tip region of the brush seal.

A particular feature of brush seals is the observed bending of the bristles towards the rotor surface under pressure loading. This leads to contact between the rotor and bristle tips, improving sealing but at the same time provoking friction and wear which may degrade the seal's performance. Experimental work by Wood (1997) has shown that the torque exerted on the rotor by a brush seal often increases as the speed of the rotor is reduced. Wood suggested that this was due to an "air-riding" effect produced in the thin film of air in the gap between the bristle tips and rotor.

A mechanism producing aerodynamic lift at the bristle tips is put forward here. This involves initial wear of the bristles whilst they are pushed radially outwards, and inclination of the bristle tip towards the rotor surface as the bristles deflect radially inwards. This is described more fully in section 2 below. Such effects might have occurred in Wood's experiments and could be used to manufacture a brush seal with significant aerodynamic lift at the bristle tips and hence improved wear characteristics.

Further details of how the inclined tip might be produced in practice are given in the next section. For convenience, the inclined tip is represented in the CFD models by the addition of a "solid wedge" to the bristle tips. This and the CFD models are also explained in section 2. CFD results for flow in the tip region of a brush seal are then given in sections 3 and 4 . Results in section 3 do not include axial flow and assume 
incompressible flow. Those in section 4 include axial flow and assume compressible flow. Heat transfer effects including heat conduction in the bristles and heat generation due to contact friction are also considered in section 4. Conclusions are given in section 5 .

\section{GEOMETRY AND NUMERICAL METHOD}

\subsection{The effect of relative movement on rotor and bristle tip contact}

Consider the single bristle shown in Fig. 2a. For simplicity, the bristle is assumed to be rigid and hinged at its root. Aerodynamic 'blow-down' forces keep the bristle tip in contact with the rotor, which is initially a distance $s$ from the bristle root. Suppose that the radial distance $s$ increases by an amount $\Delta s$, as shown in Fig. $2 \mathrm{~b}$, and that the bristle blows down on to the rotor. In this case, the bristle tip will be at an angle $\phi$ to the rotor, as shown. This angle is given by the following equation:

$$
\cos (\theta-\phi)=\cos \theta(1+\Delta s / s)
$$

where $\theta$ is the initial bristle lay angle. For small values of $\Delta s / s$, this may be approximated by:

$$
\phi=\frac{\Delta s}{s \tan \theta},
$$

where $\phi$ is in radians.

For Wood's experiments, centrifugal growth of the rotor gives $\Delta s \approx 0.05 \mathrm{~mm}$, and representative values of $s$ and $\theta$ are $10 \mathrm{~mm}$ and $60^{\circ}$ respectively. These values give a value of $\phi$ of $0.17^{\circ}$. For more extreme conditions, much bigger values of $\phi$ are possible. For example, $\Delta s / s=0.1, \theta=45^{\circ}$ gives $\phi=6.1^{\circ}$.

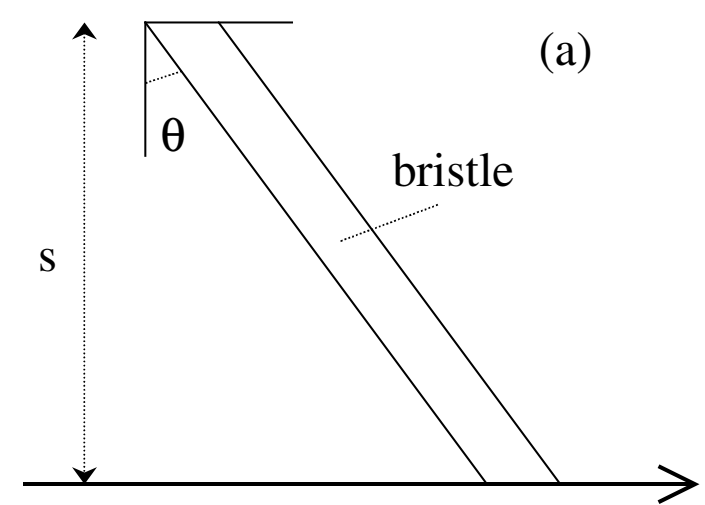

rotor

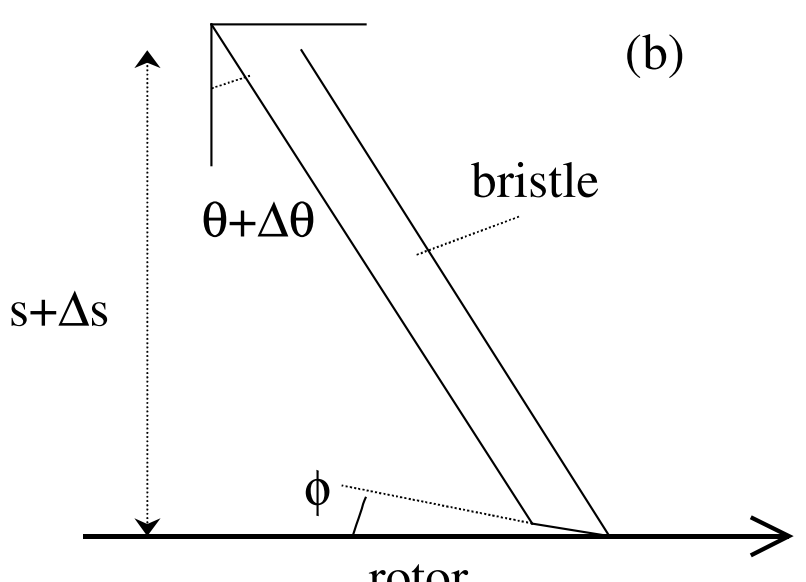

rotor

Fig. 2. Idealised representation of a single bristle in a brush seal.

In practice, wear of the bristles at high speed conditions, where centrifugal growth of the rotor is at a maximum, might lead to inclination of the tip at lower speed conditions. Deliberate production of inclined tip bristles might be achieved through abrasion using an oversized rotor. 


\subsection{CFD model bristle geometry}

In all the CFD models considered here, the bristles are assumed to be of circular cross-sectional area (elliptical when projected onto the rotor surface), and no bending of the bristles is considered. Solution domains are confined to the region of the bristle tips, this being the area of interest for this study. The basic geometry of each bristle considered here, which is typical of those occurring in a real brush seal, is shown in Fig. 3 below and has the following characteristic data:

Length of bristle included in solution domain $H=0.736 \mathrm{~mm}$

Bristle radius $R=0.075 \mathrm{~mm}$

Clearance gap between individual bristles $=R / 5=0.015 \mathrm{~mm}$

Lay angle $\theta=45^{\circ}$

In addition, and unless specified otherwise, rotor velocity $U=100 \mathrm{~m} / \mathrm{s}$. Typical bristle to rotor clearances $(\delta)$ considered here are of order $0.001 \mathrm{~mm}$. Assuming standard properties of air, these conditions give Reynolds numbers of about 100 based on interbristle spacing and 7 based on rotor clearance.

Of particular interest is the effect of the bristle tip inclination on the aerodynamic forces on the bristle. To introduce a tip angle, a solid wedge was added to the datum geometry. The wedge is of elliptical cross sectional area as projected onto the rotor (i.e. the $x y$-plane) and is angled from this plane with angle $\phi$. (see Fig. 3). As will be described below, this basic bristle geometry was used in both rectangular and hexagonal packing arrangements.

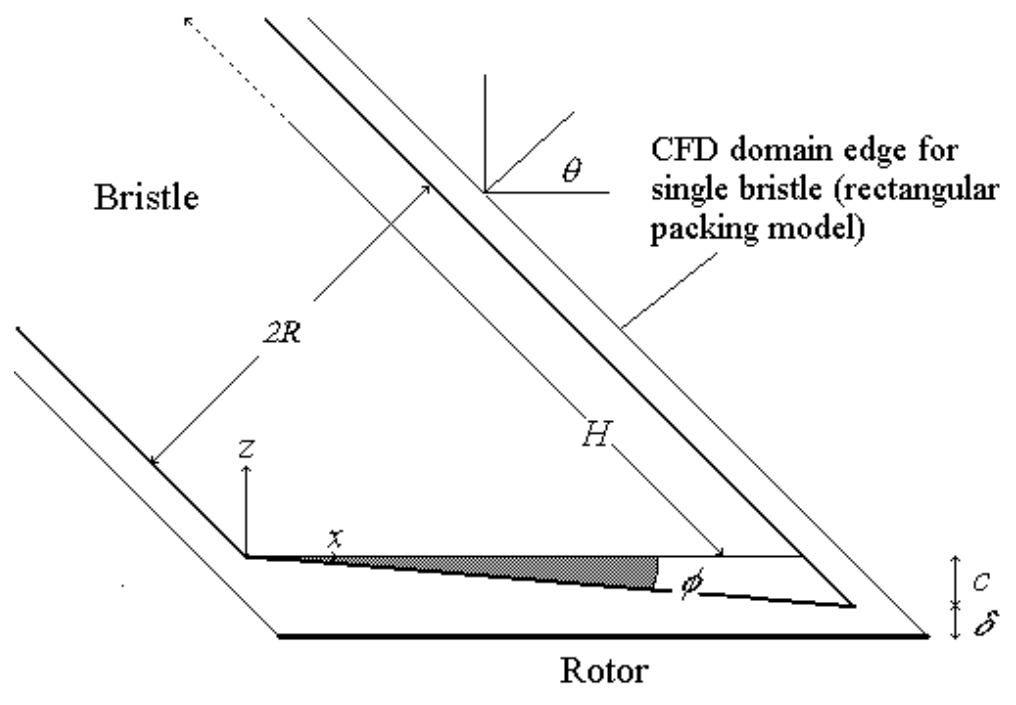

Fig. 3. Geometry for a single bristle with an angled tip.

\subsection{CFD grid generation and solution}

In order to avoid geometrical problems associated with meshing the model and allow flow between the bristles, a thin gap between the bristles was imposed. The geometry and mesh were created using GAMBIT (version 1.3.0). Due to the complexity of the geometry, it was not straightforward to create structured meshes. Unless otherwise stated, fully unstructured tetrahedral grids were used. The domain was split into two parts. For the tip region, $-(c+\delta)<z<0.10203 \mathrm{~mm}$, an approximate $20 \%$ spacing based 
upon the shortest edge in the computation domain was employed (in most cases this was equal to the minimum clearance $\delta$ ). For $0.10203 \mathrm{~mm}<z<H \cos \left(45^{\circ}\right)=0.520330$ $\mathrm{mm}$, an approximate $50 \%$ spacing was employed. It is necessary to first mesh the finer lower grid in the domain. An example of a CFD grid used is shown in Fig. 4.

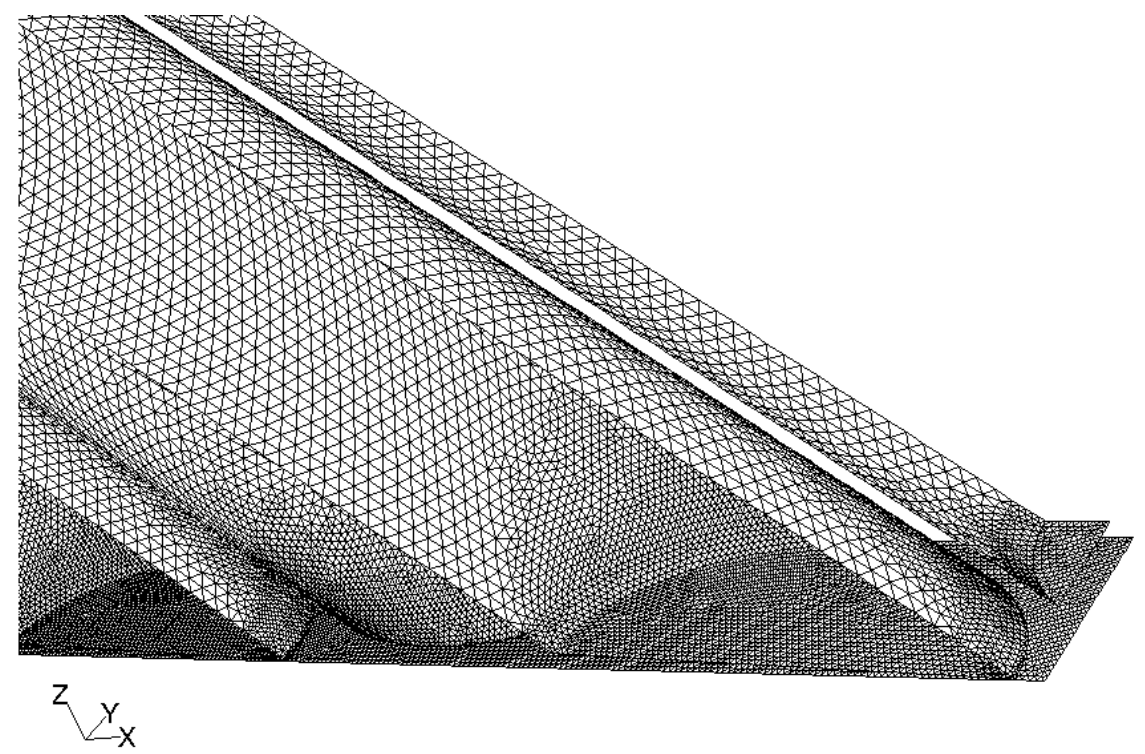

Fig. 4. Close-up view of surface grid on bristle (near to tips) for an hexagonal packing arrangement.

Laminar flow was assumed throughout. Incompressible flow solutions were obtained using FLUENT version 5.5.14, and these are discussed in section 3. Fully compressible solutions with solid heat conduction modelling in the bristles are included in section 4. Unless otherwise stated the fluid properties assumed correspond to air at standard atmospheric conditions.

Periodic boundary conditions were imposed along the direction parallel to the rotor motion (ie. in the $x$-direction in the CFD model). For cases with no axial pressure gradient (ie. in the $y$-direction), symmetry conditions were imposed on the constant $y$ boundaries. In this case the flow is entirely driven by shear forces induced by the moving rotor surface. No-slip, no penetration boundary conditions have been applied at the upper $z$ plane boundary and on the bristle and rotor surfaces. For models with an axial flow the inlet and outlet lie on planes of constant $y$, with flow in the negative $y$ direction. Total pressure, total temperature and flow normal to the boundary are specified at inlet. The static pressure was specified at the outlet plane.

All of the solutions were obtained using a second-order accurate segregated solver with the pressure-correction algorithm. Gradients were estimated using a cell-centred scheme with second order upwind differencing. The well-known SIMPLE iterative algorithm was used with the pressure field solution being linked to the continuity equation. Under-relaxation was employed to ensure convergence. For the compressible flows in Section 4, viscous heating was also included in the calculations. As expected, for a case in which the variation in pressure is about $6 \%$ of the absolute pressure, relatively small differences were found between the pressure distributions for incompressible and compressible flow calculations. 
All of the results presented here are believed to have properly converged to a steady state. The residuals reduce by at least a factor of $10^{3}$ from their starting values. Although not shown, it has been confirmed that errors in the force/momentum balances in the $\mathrm{x}$ direction are acceptably small. Also, for compressible flows with heat transfer modelling, the total energy inputs and outputs were found to be in good agreement.

Numerical errors due to mesh dependency have also been considered. Fig. 5 shows results from two different meshes for the pressure under the bristle tip centreline for one of the cases studied. It can be seen that slight mesh-dependency of the solutions is noticeable. However these discrepancies are considered to be within the acceptable range of accuracy of this study.

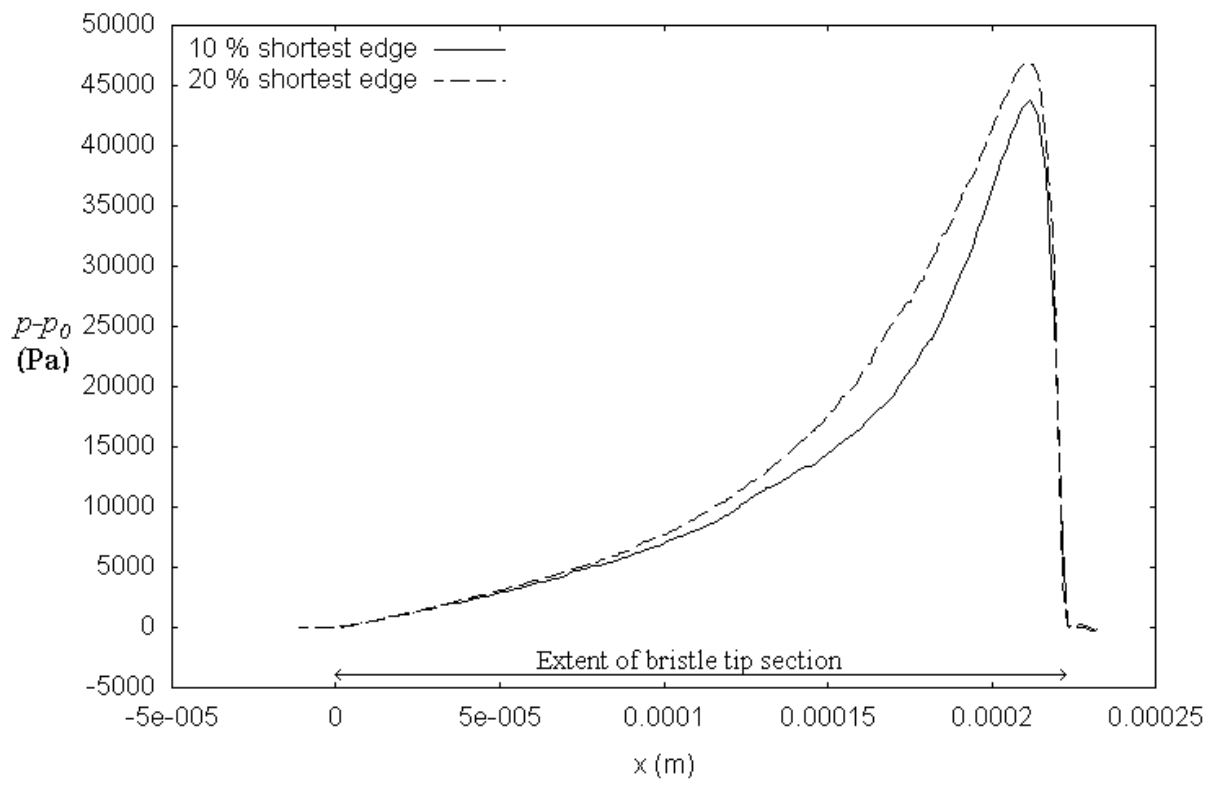

Fig. 5. Comparison of the gauge static pressure distributions on the bristle tip centreline for case $G\left(\phi=2.4^{\circ}\right)$ for two different meshes (i.e. meshes generated using 10 or $20 \%$ shortest edge spacing).

\section{RESULTS WITHOUT AXIAL FLOW}

\subsection{Summary of CFD results for rectangular packing}

A series of CFD solutions were obtained to show the effects of tip geometry on aerodynamic lift. These calculations assumed rectangular packing with no axial flow. Table 1 summarizes the solutions obtained with various tip angles and clearances. Note that the lift $L$ and $\operatorname{drag} D$ were computed by integrating over the entire bristle for lift, and the entire rotor for drag, i.e.

$$
L=\int_{\text {bristle }}\left(p-p_{0}\right) \mathbf{e}_{z} \cdot \mathbf{n} d S, \quad D=\int_{\text {rotor }} \tau_{s} . \mathbf{e}_{x} d S
$$

Here $\boldsymbol{e}_{x}, \boldsymbol{e}_{z}$ and $\boldsymbol{n}$ are unit vectors in the $x, z$ and surface normal directions, $\boldsymbol{\tau}_{\mathrm{s}}$ is the viscous stress vector at the surface, and $p_{0}$ is the pressure at a reference point in the gap between bristles. Based on the theory described later, a non-dimensional lift $\Phi$ 
$(=L / \mu U l)$ will is presented and the drag $D$ reported as a lift-to-drag ratio $L / D$. Note that the pressure level in the CFD solution is arbitrary for these incompressible cases. Cases $\mathrm{H}$ to $\mathrm{J}$ in the table are for a 'cut tip' design in which the tip of the angled bristle has been sliced off to give a region with uniform clearance downstream of the tapered area. This is discussed further below.

The results are discussed in the following subsections but, to show the general form of the solutions, the pressure distribution on the rotor for case $\mathrm{E}$ is given in Fig. 6. This shows the expected result that the static pressure reaches a maximum a little upstream of the position of minimum clearance to the bristle tip. This is in contrast to a much more uniform pressure distribution observed for the case without the angled tip. As shown for case A in table 1, a 'flat' tip with an inclication angle of zero gives very little aerodynamic lift. Clearly, the tip angle has a significant impact upon the flow field. Further illustration of the pressure field under the bristle tip is given in Fig. 7. This shows the pressure distribution along the bristle tip centreline for some of the cases in table 1. For cases $\mathrm{E}, \mathrm{F}$ and $\mathrm{G}$, the maximum rotor to bristle tip clearance $(c+\delta)$ remains fixed. As the tip angle $\phi$ increases, the minimum clearance $(\delta)$ reduces and the peak pressure increases dramatically. The introduction of the cut tip for case $\mathrm{H}$, clearly brings forward the point of maximum pressure.

\begin{tabular}{|c|c|c|c|c|c|c|}
\hline Case ID & $\begin{array}{c}\text { Tip angle } \\
\phi \\
(\text { degrees })\end{array}$ & $\begin{array}{c}\text { Minimum } \\
\text { tip-rotor } \\
\text { clearance } \delta \\
(\mu \mathrm{m})\end{array}$ & $\begin{array}{c}\text { Wedge } \\
\text { height } c \\
(\mu \mathrm{m})\end{array}$ & $\begin{array}{c}\text { Max }\left(p-p_{0}\right) \\
(\text { bar })\end{array}$ & $\begin{array}{c}\text { Lift } \\
\Phi \\
=L / \mu U l\end{array}$ & $\begin{array}{c}\text { Lift/ } \\
\text { Drag } \\
=L / D\end{array}$ \\
\hline $\mathrm{A}$ & 0.0 & 9.797 & 0 & 0.006 & 6.46 & 0.312 \\
\hline $\mathrm{K}$ & 0.15 & 0.517 & 0.5568 & 0.72 & 2529 & 13.5 \\
\hline $\mathrm{B}$ & 0.3 & 0.517 & 1.117 & 0.85 & 2362 & 15.7 \\
\hline $\mathrm{C}$ & 0.6 & 0.517 & 2.245 & 0.78 & 1692 & 14.3 \\
\hline $\mathrm{D}$ & 1.2 & 0.517 & 4.539 & 0.60 & 953 & 11.4 \\
\hline $\mathrm{E}$ & 2.0 & 2.121 & 7.676 & 0.070 & 187 & 4.41 \\
\hline $\mathrm{F}$ & 2.2 & 1.322 & 8.475 & 0.14 & 299 & 6.14 \\
\hline $\mathrm{G}$ & 2.4 & 0.517 & 9.280 & 0.45 & 540 & 8.72 \\
\hline $\mathrm{H}$ & 2.4 (cut) & 2.121 & 7.676 & 0.15 & 336 & 6.35 \\
\hline $\mathrm{I}$ & 2.8 (cut) & 0.517 & 9.280 & 0.94 & 1075 & 11.0 \\
\hline $\mathrm{J}$ & 3.2 (cut) & 0.517 & 9.280 & 0.91 & 1269 & 10.2 \\
\hline
\end{tabular}

Table 1. Summary of incompressible solutions for various tip angles $\phi$ and clearances $\delta$. Unless specified otherwise, the bristle tip was uncut. 


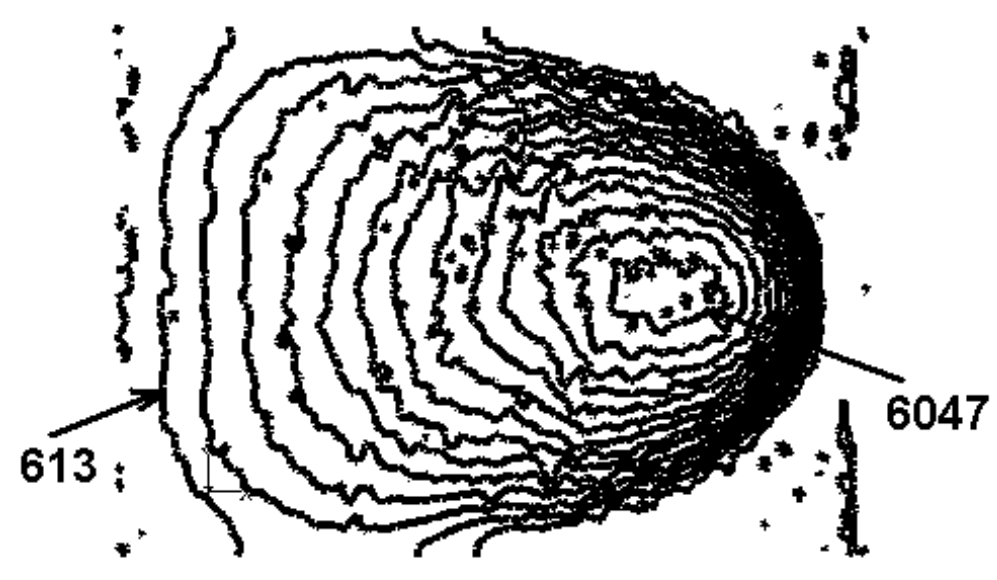

Fig. 6. Surface gauge pressure contours (Pa) on the rotor for case $E\left(\phi=2^{0}\right)$. $($ Contour interval $=453 \mathrm{~Pa})$

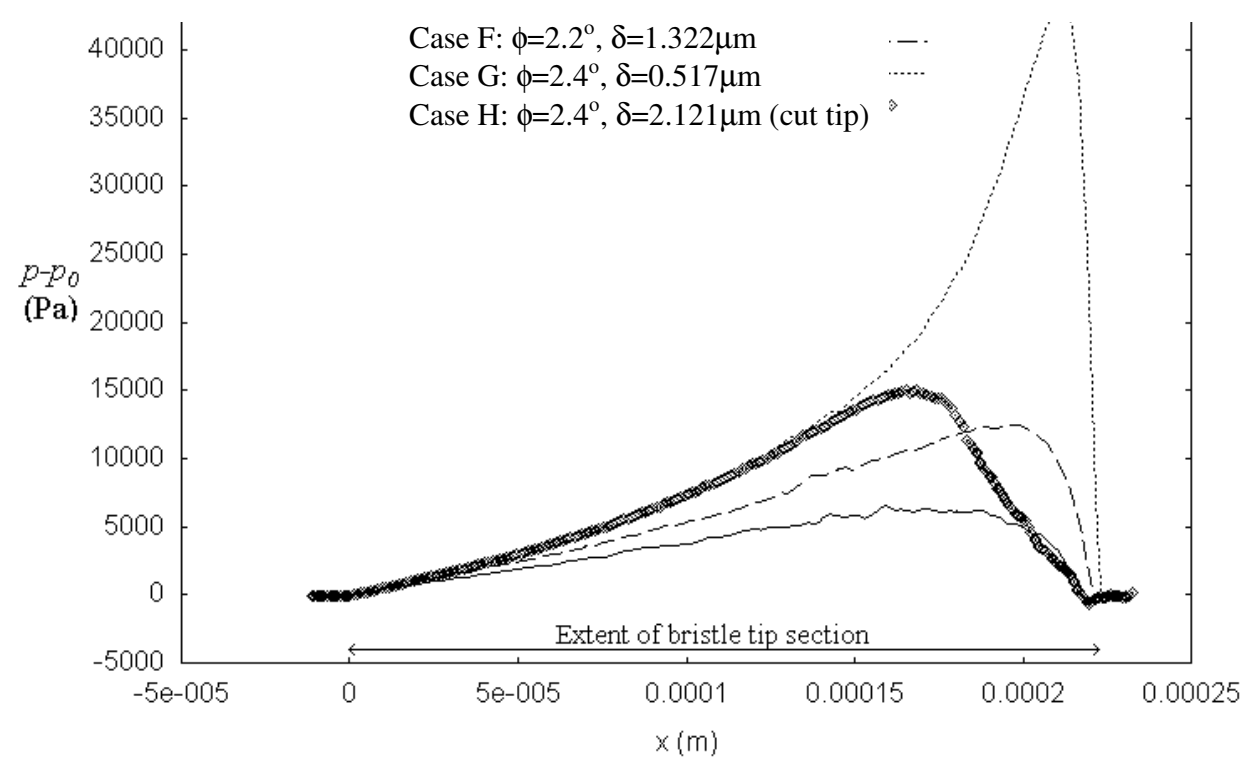

Fig. 7. Gauge static pressure distributions on the bristle tip centreline for various examples.

\subsection{Effect of tip angle with constant minimum clearance $\delta$}

In practice, the effective minimum clearance that can be achieved maybe limited by surface roughness. A typical value for rotor roughness heights is thought to be about $0.5 \mu \mathrm{m}$, and so it is of interest to see how lift varies with tip angle with the minimum clearance fixed at this value. This is shown by the results for cases $\mathrm{K}, \mathrm{B}, \mathrm{C}, \mathrm{D}$ and $\mathrm{G}$ in Table 1, for which the variation in lift is given in Fig.8. In this figure the data points are joined by straight lines as a visual aid. It is clear that as $\phi$ is reduced, lift increases. Since no lift is expected for zero inclination angles a rapid fall off in lift must occur at very low angles. This will be discussed further in section 3.4 below. It can also be seen from table 1 that the drag on the rotor is an order of magnitude less than the lift for these cases with the lift to drag ratio having values ranging from 8.72 to 15.7 . 


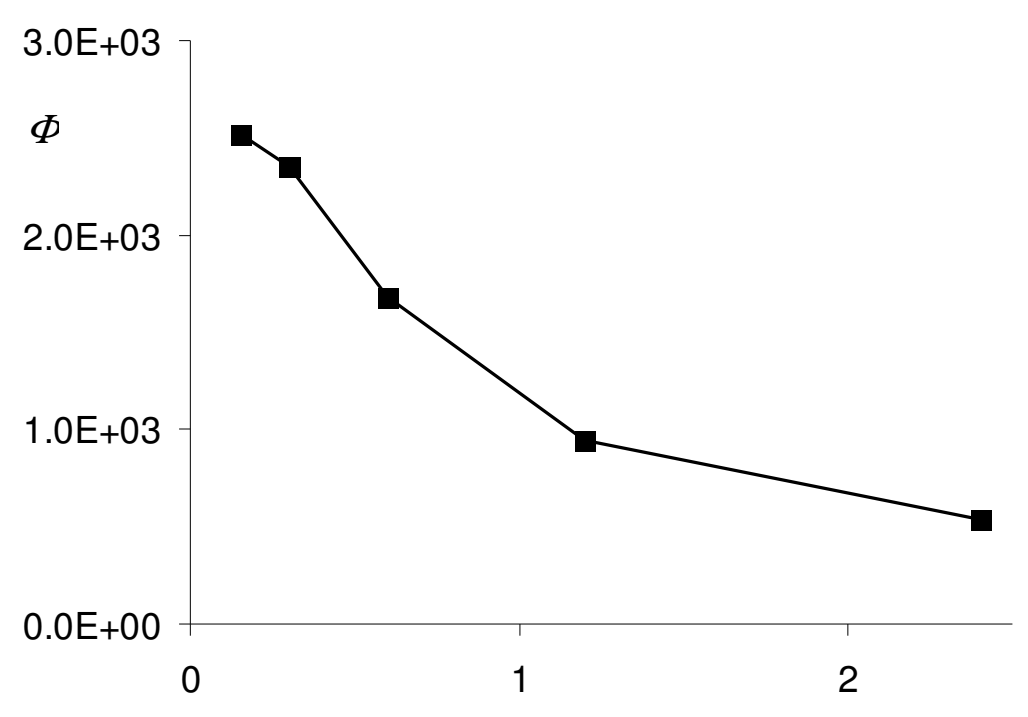

Tip angle $\phi$ (degrees)

Fig. 8: Variation of net lift force with tip angle $\phi$.

\subsection{A cut tip geometry}

As mentioned above, a modified angled tip geometry has also been considered., This geometry is shown in fig. 9 and includes a flat 'cut' near the tip. Such a geometry might be produced by wear as the bristle contacts the rotor. The effect of this change is illustrated in fig. 7. Here cases $\mathrm{H}$ and $\mathrm{E}$ have the same minimum and maximum clearances $(\delta=2.121 \mu \mathrm{m}, \delta+c=9.797 \mu \mathrm{m})$ but case $\mathrm{H}$ has a flat region so its taper angle $\left(\phi=2.4^{\circ}\right)$ is greater than that for case $\mathrm{E}\left(\phi=2^{\circ}\right)$. A substantial increase in lift for Case $\mathrm{H}$ is apparent. Thus, the cut tip design does appear to yield better performance than the simple angled tip with the same clearance $\delta$. A comparison of Cases $G, I$ and $\mathrm{J}$ in Table 1 shows the cut also gives improved lift performance at lower clearances, although it is not clear what the optimum length of the cut is.

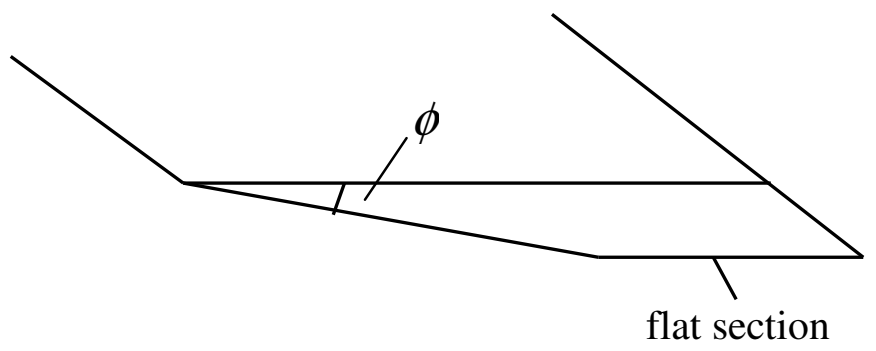

Fig. 9. Example of a bristle with a cut tip geometry.

\subsection{Comparison with theoretical results}

It can be shown using standard lubrication theory and assuming two dimensional flow that the solution for the pressure increase $\Delta p\left(=p-p_{o}\right)$ at the bristle tip centreline is given by (see, for example, Acheson 1990):

$$
\frac{\Delta p^{*}(x)}{6 \mu U l}=\frac{\left(f_{1}-f\right)\left(f_{2}-f\right)}{\left(f_{2}^{2}-f_{1}^{2}\right) f^{2}} .
$$

This assumes a linear decrease in clearance $f$ from $f_{l}$ at $x=0$ to $f_{2}$ at $x=l$. Here, $l$ is the projected bristle tip diameter onto the $x y$-plane and $f=f(x)$ is the gap between the 
bristle tip surface and the moving rotor surface. The superscript ${ }^{*}$ is used to denote a solution of the 2D Reynolds equation. The Reynolds equation is valid for small values of $\varepsilon \operatorname{Re}$, where the aspect ratio $\varepsilon$ and Reynolds number Re are defined here by:

$$
\varepsilon=\frac{f_{1}}{l}, \quad \operatorname{Re}=\frac{\rho U \delta}{\mu} .
$$

For the conditions considered here $\varepsilon$ Re is generally of order 1 .

Although the above 2D solution is not strictly valid for the $3 \mathrm{D}$ case considered here (due to flow in the $y$-direction), some qualitative agreement with the CFD results is expected. The pressure increase given by the $2 \mathrm{D}$ solution is scaled as follows:

$$
\Delta p(x)=\eta \Delta p^{*}(x)
$$

Here, $\eta$ is the ratio of the maximum values of $\Delta p$ obtained using the 3D CFD results to the theoretical 2D results. From the solutions obtained in this study on the bristle centreline, $\eta$ has an average value of approximately 0.36 . As can be seen in

Fig. 10, the above expressions with this scaling yield fair approximations to the incompressible CFD solution on the bristle centreline. In particular, the overall shape for the pressure distribution, including the approximate location of the peak pressure is predicted. Note that the CFD pressure distribution in fig. 10, which are interpolated from the unstructured mesh) shows some irregularity. This occurred for some conditions but, as shown in fig, 7, is less apparent in the results showing higher aerodynamic lift.

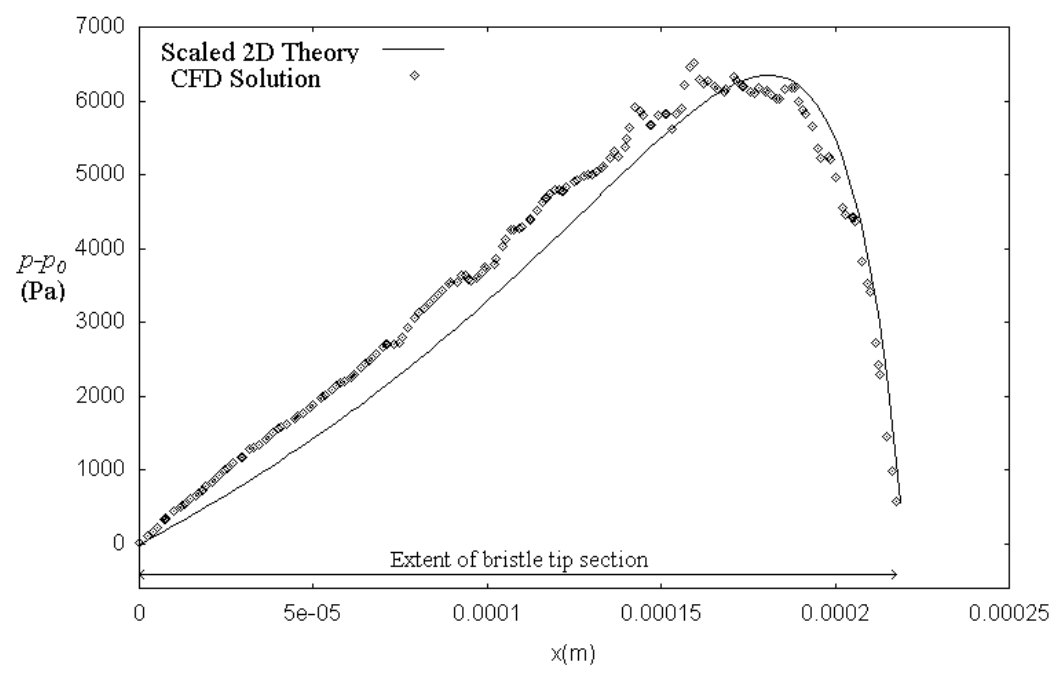

Fig. 10. Comparison of theoretical and CFD results for Case $E\left(\phi=2^{\circ}\right)$ for the pressure increase $\Delta p$ on the bristle tip centreline (i.e., $y=0$ plane).

It is interesting to see how the lift given by the $2 \mathrm{D}$ solution varies with different parameters. This is shown in Fig. 11, for which the 2D solutions were obtained numerically using standard lubrication theory and assuming $l=0.212 \mathrm{~mm}, \mu=1.8 \times 10^{-5}$ $\mathrm{kg} / \mathrm{ms}$ and $U=100 \mathrm{~m} / \mathrm{s}$. No scaling has been applied to the results in this figure which applies to a $2 \mathrm{D}$ plate or pad rather than the bristle geometry. Here the lift per unit width of the pad is non-dimensionalised by dividing by $\mu \mathrm{U}$. This is equivalent to 
calculating the lift on a width $l$ of the pad and non-dimensionalising using $\mu U l$ as for the bristle tip.

Fig. 11a shows how results for an inclined pad vary with angle of inclination $\phi$ for a fixed minimum clearance $\delta=0.5 \mu \mathrm{m}$. The maximum lift occurs for $\phi=0.16^{\circ}$. At lower angles than this the lift falls rapidly as $\phi$ reduces. The reduction in lift as $\phi$ increases above $0.16^{\circ}$ is more gentle, but still very significant.

As shown in Fig. 11b, minimum clearance is also a very important parameter. Results in this figure are for a 'cut' geometry with the downstream $20 \%$ of the pad being flat, and a fixed inclination angle for the upstream section of $\phi=0.5^{\circ}$. In practice, as the clearance is reduced to very small values, the mean free path of the molecules will become significant and Knudsen number effects will be important Nevertheless substantial increases in lift are clearly possible at lower clearances.

Fig. 11c shows the sensitivity to variation of the length of the flat, downstream section of the pad in the 2D solution for the cut tip geometry of section 3.3. Here the minimum clearance and angle $\phi$ are fixed at $0.5 \mu \mathrm{m}$ and $0.5^{\circ}$, respectively. The lift is not unduly sensitive to the length of the flat section provided that it is less than $60 \%$ of the pad. The maximum lift occurs with the flat section extending over about $30 \%$ of the pad. Note, however, that for the brush seal 3D geometrical effects will be important. In particular, off-centreline minimum bristle tip clearances will be reduced by the introduction of the cut, giving further increases in lift. 


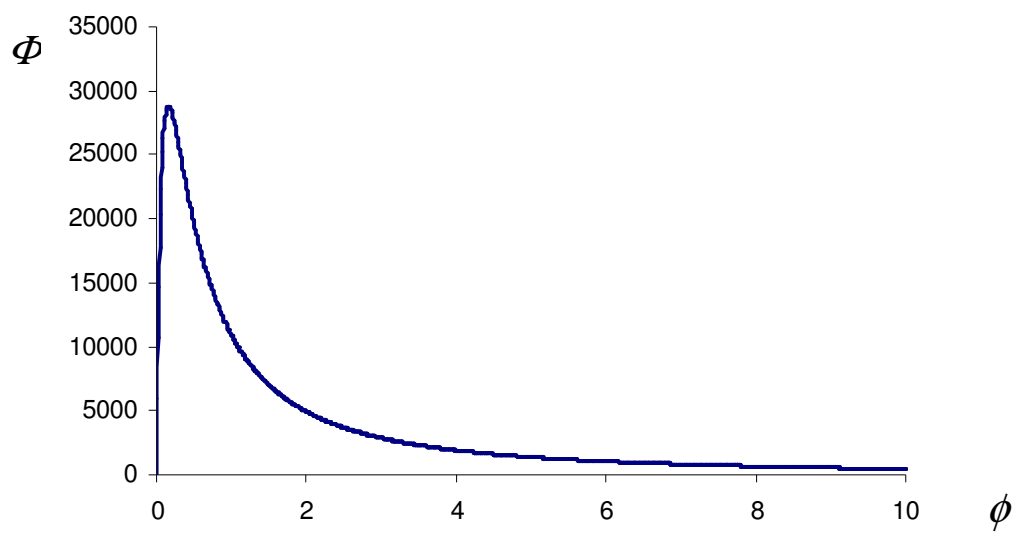

(a) 2D solution for variation of lift with tip angle $\phi(\delta=0.5 \mu \mathrm{m})$.

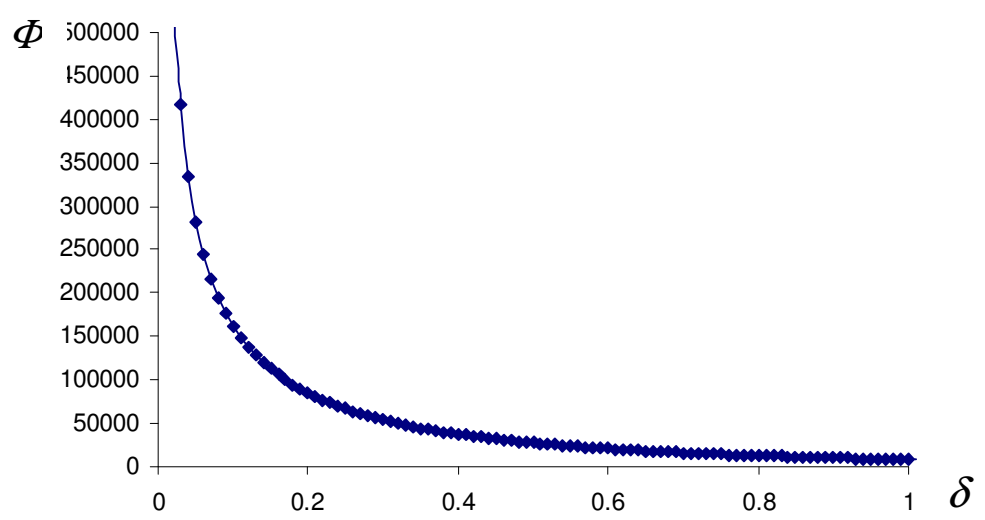

(b) 2D solution for variation of lift with minimum clearance $\delta\left(\phi=0.5^{\circ}, 20 \%\right.$ of the pad is flat).

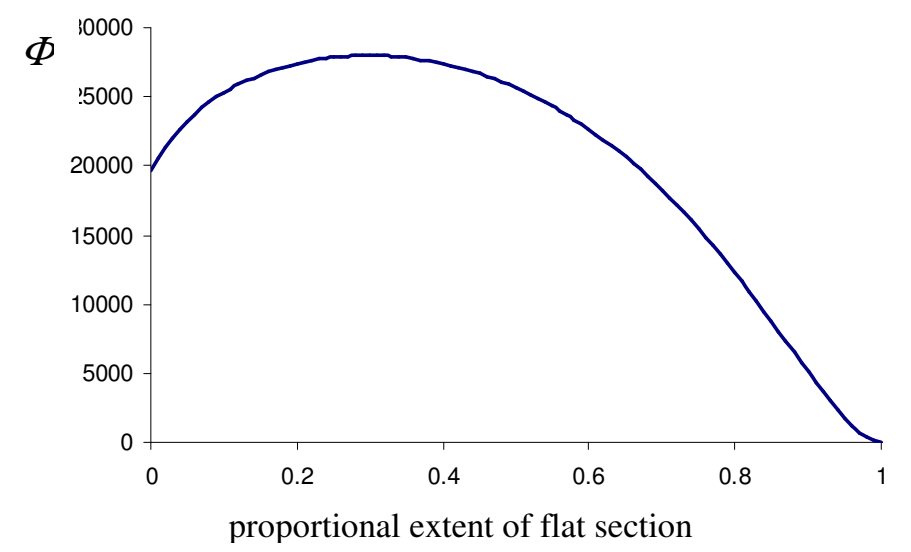

(c) variation of lift with the proportional extent of the flat section for cut pad geometries $\left(\delta=0.5 \mu \mathrm{m}, \phi=0.5^{\circ}\right)$.

Fig. 11. 2D, low Reynolds number solution 


\subsection{Reynolds number effects}

The rotor velocity and fluid density have been varied in the CFD solution for case G, so as to investigate the sensitivity to Reynolds number. Results are summarised in table 2. Here the Reynolds number is defined using the minimum clearance as in section 3.4. A small increase in non-dimensional lift $\Phi$ with Reynolds number is evident. As expected, very similar results are obtained whether the increase in $R e$ is achieved through increasing speed or through increasing fluid density.

\begin{tabular}{|c|c|c|c|c|c|c|}
\hline $\begin{array}{c}\text { Case } \\
\text { ID }\end{array}$ & $\begin{array}{c}\text { Reynolds } \\
\text { number }\end{array}$ & $\begin{array}{c}\text { Rotor } \\
\text { speed } \\
(\mathrm{m} / \mathrm{s})\end{array}$ & $\begin{array}{c}\text { Fluid } \\
\text { density } \\
\left(\mathrm{kg} / \mathrm{m}^{3}\right)\end{array}$ & $\begin{array}{c}\text { Max }(\Delta p) \\
(\text { bar })\end{array}$ & $\begin{array}{c}\text { Lift } \\
\Phi \\
=L / \mu U l\end{array}$ & $\begin{array}{c}\text { Lift/Drag } \\
=L / D\end{array}$ \\
\hline G & 3.54 & 100 & 1.225 & 0.48 & 649 & 10.1 \\
\hline G-U2 & 7.08 & 200 & 1.225 & 0.95 & 697 & 9.83 \\
\hline G-U3 & 14.16 & 400 & 1.225 & 2.23 & 775 & 9.51 \\
\hline G-D2 & 7.08 & 100 & 2.450 & 0.52 & 702 & 9.81 \\
\hline G-D3 & 14.16 & 100 & 4.900 & 0.54 & 776 & 9.51 \\
\hline
\end{tabular}

Table 2. Summary of incompressible solutions for various rotor speeds $U$ and densities $\rho$ for case $\mathrm{G}\left(\phi=2.4^{0}, \delta=0.517 \mu \mathrm{m}\right)$.

\subsection{Effects of bristle packing arrangement}

To check sensitivity to the bristle packing arrangement case E was repeated for a hexagonally-packed arrangement which is probably more representative of real brush seals. In this model two half-bristles are considered instead of the complete one considered for the rectangular-packing arrangement. It was found that hexagonal packing gave a slightly lower lift force than with rectangular packing. This is shown in table 3 .

\begin{tabular}{|c|c|c|}
\hline $\begin{array}{c}\text { Packing } \\
\text { arrangement }\end{array}$ & $\begin{array}{c}\text { Lift } \\
\Phi \\
=L / \mu U l\end{array}$ & $\begin{array}{c}\text { Lift/ } \\
\text { Drag } \\
=L / D\end{array}$ \\
\hline Rectangular & 187 & 4.41 \\
\hline Hexagonal & 182 & 4.74 \\
\hline
\end{tabular}

Table 3. Comparison of hexagonal and rectangular packing arrangements

$$
\left(U=100 \mathrm{~m} / \mathrm{s}, \phi=2^{\circ}, \delta=2.121 \mu \mathrm{m}, c=7.676 \mu \mathrm{m}\right) \text {. }
$$

\subsection{Comparison with experimental data}

Wood's experiments included torque measurements for pairs of $0.14 \mathrm{~mm}$ diameter bristle seals with a lay angle of $60^{\circ}$, and about $5 \times 10^{4}$ bristles per seal. Typically, combined torques on the rotor (of radius approximately $0.164 \mathrm{~m}$ ) were in the range 5 to $30 \mathrm{Nm}$ for the two seals. Assuming a friction factor of 0.3 , this corresponds to a normal force on the rotor of $10^{-3}$ to $6 \times 10^{-3}$ Newtons per bristle. At $10,000 \mathrm{rpm}$, the rotor speed in the experiment is about $170 \mathrm{~m} / \mathrm{s}$. For comparison with the present results this gives a non-dimensional lift $\Phi$ of about 1000 to 7000 Note also that compared to the $45^{\circ}$ lay angle used above, Wood's $60^{\circ}$ lay angle will give a larger 
area and peak pressure under the bristle tip, increasing lift by more than the linear scaling with $l$ used in the non-dimensionalisation. Thus for the experimental conditions, the aerodynamic lift forces, as indicated in the present CFD studies, could certainly be significant, and account for the observed variation of torque with speed.

As noted above, surface roughness may limit the minimum clearance that can be achieved. The lift obtained in practice is also likely to be sensitive to surface finish. There is little or no experimental data available for the effect of surface roughness on brush seal behaviour, but it has been shown by Guardino et al (2002) that surface roughness does affect the lift achieved in a Rayleigh pad.

\section{RESULTS WITH AXIAL FLOW}

In this section, an idealised section of a brush seal consisting of a row of 4 hexagonal or rectangular packed bristles is considered. The bristle tip angle $\phi=2^{\circ}$ and minimum clearance $\delta=0.517 \mu \mathrm{m}$. Periodic conditions were again used in the $x$-direction, and a pressure difference was imposed in the axial $y$-direction. On the upstream axial plane the flow is aligned with the $y$-axis and inlet total temperature and total pressure were specified as $300 \mathrm{~K}$ and 1.5 bar. The sign of the pressure difference is such as to give a flow in the negative $y$-direction, and the downstream static pressure is specified as 1 bar. No-slip conditions are applied on all solid surfaces, with $U=100 \mathrm{~m} / \mathrm{s}$ on the rotor.

The effects of heat generated due to viscous dissipation and contact friction, and heat conduction through the bristles are included in the models. Solid surfaces on the constant $y$ boundaries and the rotor were assumed adiabatic. When specified, the temperature at the bristle top surfaces (ie. plane of maximum $z$ ) was set equal to $300 \mathrm{~K}$. The material properties of the bristles (see table 4) were chosen to be representative of Haynes-25, which is a cobalt/nickel-based alloy. The air was treated as a perfect gas with Sutherland's viscosity-temperature law assumed (see, for example, Anderson (1989)).

\begin{tabular}{|l|c|c|}
\hline & Air & Bristle \\
\hline Density $\left(\mathrm{kg} / \mathrm{m}^{3}\right)$ & Ideal-gas law & 8900 \\
\hline Specific heat $C_{P}(\mathrm{~J} / \mathrm{kg}-\mathrm{K})$ & 1006.43 & 460.0 \\
\hline Thermal conductivity $k(\mathrm{~W} / \mathrm{m}-\mathrm{K})$ & 0.0242 & 96 \\
\hline Viscosity & Sutherland's law & - \\
\hline
\end{tabular}

\section{Table 4. Fluid and material properties used for coupled fluid/solid modelling.}

Solution of the energy equation for the heat transfer within the bristles, in addition to solving the Navier-Stokes' equations in the flow domain, required meshing of the bristles. Similar mesh densities were used to those in section 3. Fig. 4 shows a typical grid on the surface of the bristle. The interior grid is not shown, but has been meshed using the same criteria as for the flow around the bristle. The unstructured grid used for the hexagonal packing simulation consisting of approximately 1.6 million cells. For the rectangular packing geometry, an unstructured grid consisting of approximately 1.2 million cells was employed. 
Heat generation due to frictional contact between the bristle tips and rotor was modelled as a heat source in the bristle tip. For convenience, this heat input was assumed to be uniformly distributed over the wedge volume. Denoting the normal reaction force acting on the bristle due to solid contact as $R$, and the coefficient of friction as $\zeta$, the heat source $Q$ per unit volume of the wedge can be estimated from the rate of work done by this frictional force as follows:

$$
Q=\frac{\zeta R U}{V_{\text {wedge }}}
$$

where $V_{\text {wedge }}$ is the volume of the solid wedge. For $\zeta=0.3$ which is a representative value for nickel-based alloys in sliding contact with steel (see, for example, Hutchings 1992), $R=10^{-3} \mathrm{~N}$, and $U=100 \mathrm{~m} / \mathrm{s}$, this equation gives $Q=3.13 \times 10^{11} \mathrm{~W} / \mathrm{m}^{3}$ which is the value used here.

Three different solutions were obtained. Hexagonal and rectangular packing cases were both calculated with temperature specified on the outer $z$-plane which cuts the bristles at a distance $0.736 \mathrm{~mm}$ from the bristle tips and defines the extent of the solution domain.. The third solution was for hexagonal packing with an adiabatic boundary condition on the outer $z$-plane. This prevented energy transport out of the domain through heat conduction along the bristles. In addition to the usual convergence monitoring of residuals, overall energy balances for these solutions were also checked, and errors were found to be within $2.5 \%$ of the specified frictional heat generation.

Figs 12 and 13 show velocity contours on a central portion of a plane near the rotor for the hexagonal and rectangular packing solutions. In these figures, axial flow is downwards and rotor motion is from left to right. It is clear that axial velocities of similar magnitude to the rotor speed occur in the flow between the bristles. The mass flows given by these two solutions are shown in table 5. Allowing for the different widths of the domains (in the x-direction) for the two solutions, the leakage flow for rectangular packing is 1.64 times that for hexagonal packing. The leakage flow is of comparable magnitude to that which might be expected from Wood's lower pressure experimental measurements. However, considering the 3D nature of the flow, the restriction here that no flow passes through the outer z-boundary, and the idealised packing assumed, the significance of this comparison is questionable.

\begin{tabular}{|c|c|c|c|}
\hline Packing & $\begin{array}{c}\text { Rotor } x \text {-direction } \\
\text { mass flux }(\mathrm{kg} / \mathrm{s})\end{array}$ & $\begin{array}{c}\text { Axial } y \text {-direction } \\
\text { mass flux }(\mathrm{kg} / \mathrm{s})\end{array}$ & $\begin{array}{c}\text { Axial flow per unit } \\
\text { face area }\left(\mathrm{kg} / \mathrm{m}^{2} \mathrm{~s}\right)\end{array}$ \\
\hline Rectangular & $1.60 \times 10^{-6}$ & $2.29 \times 10^{-6}$ & 18.7 \\
\hline Hexagonal & $0.260 \times 10^{-6}$ & $2.37 \times 10^{-6}$ & 11.4 \\
\hline
\end{tabular}

Table 5. Comparison of mass fluxes for rectangular and hexagonal packing. 


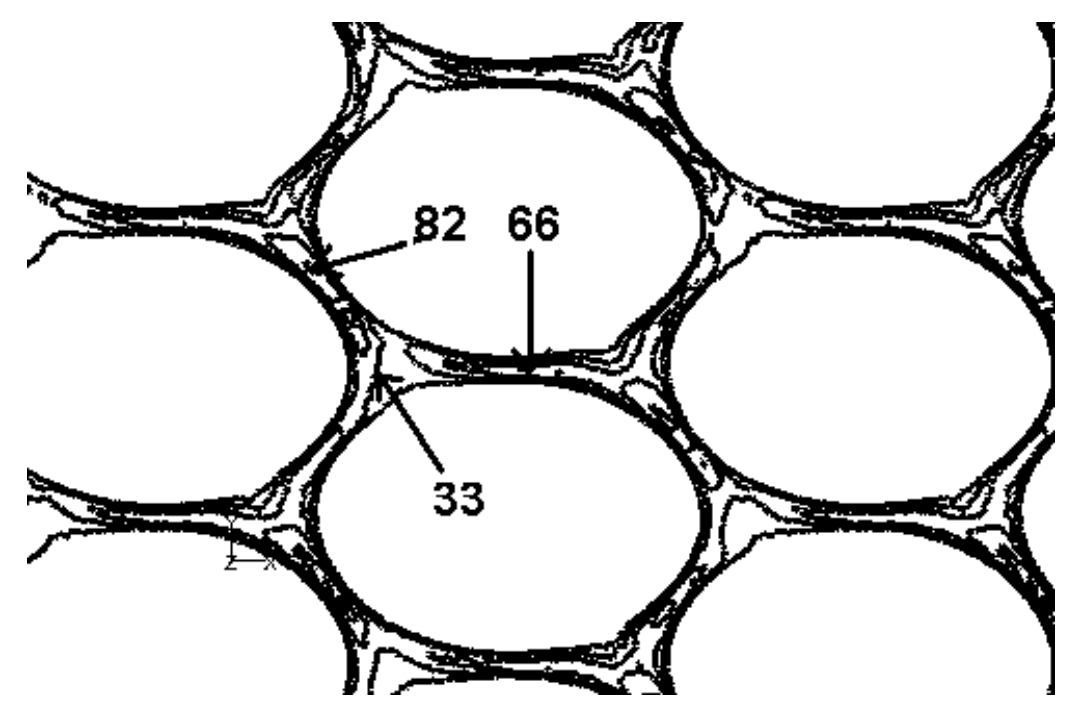

Fig. 12: Contours of velocity magnitude for hexagonal packing on plane $z=0 \mathrm{~mm}$ parallel to rotor. $($ Contour interval $=16.4 \mathrm{~m} / \mathrm{s})$

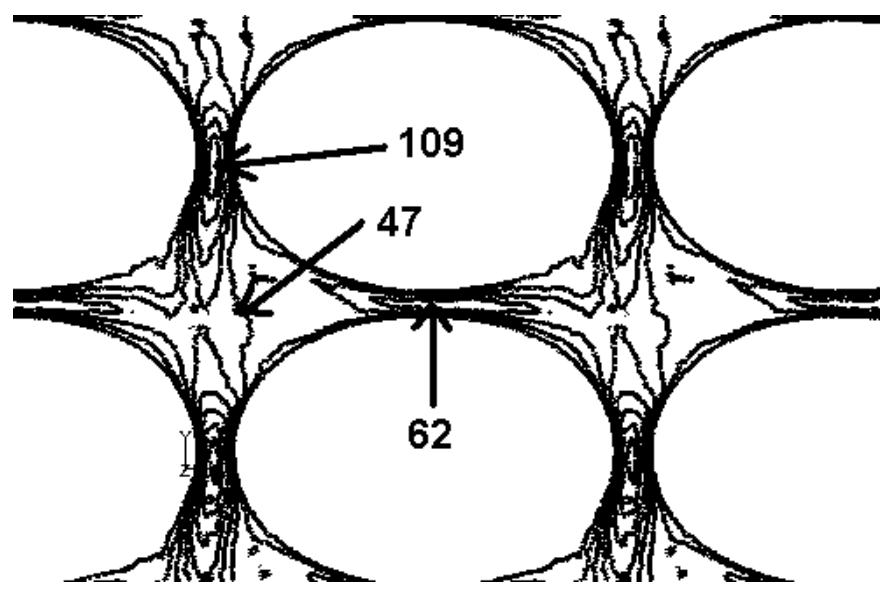

Fig. 13. Contours of velocity magnitude for rectangular packing on plane $z=0 \mathrm{~mm}$ parallel to rotor. $($ Contour interval $=15.6 \mathrm{~m} / \mathrm{s})$

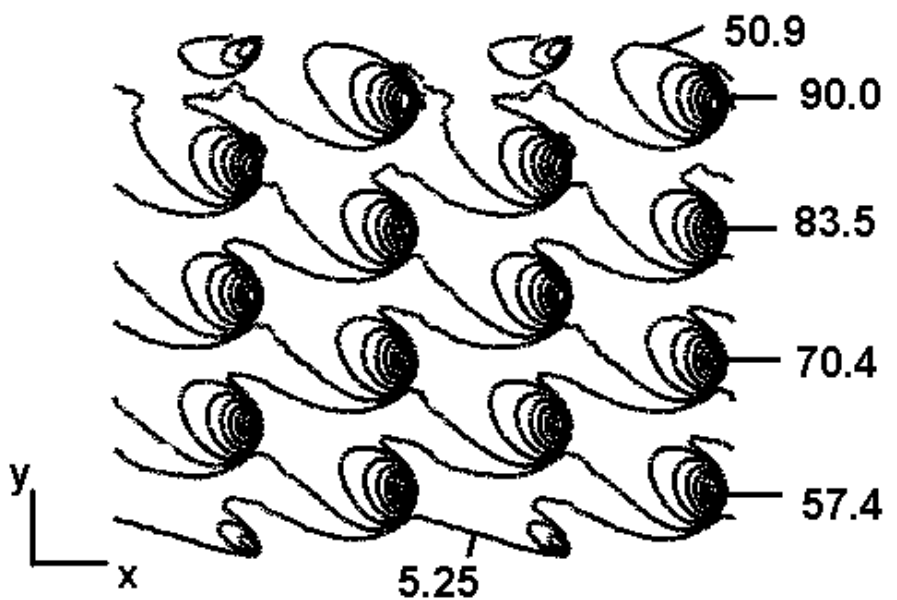

Fig. 14. Pressure contours on rotor for case with heat generation due to solid contact friction and heat conductive bristle tops. $($ Contour interval $=6.52 \mathrm{kPa})$ 
points of maximum and minimum clearance, and thus an appreciable lift force, as expected from the calculations without axial flow. Estimating the lift force by integrating pressure on the rotor and comparing with the mean of the inlet and exit pressures gives an average lift force of about $235 \times 10^{-6} \mathrm{~N} / \mathrm{bristle}$. This is in reasonable agreement with the value of $219 \times 10^{-6} \mathrm{~N} /$ bristle obtained from the solution without axial flow for this configuration. The rectangular packing solution similarly confirms the degree of lift expected from the solutions without axial flow.

Rotor temperatures for the hexagonal packing solution are shown in Fig. 15. Some cooling by the leakage flow is apparent close to the inlet. Further into the pack heat conduction along the bristle dominates, with the air apparently no longer picking up heat. The dominance of heat conduction was shown by the solution with an adiabatic condition on the bristle ends (at the outer $z$-boundary). The temperature distribution in the pack showed largely uniform bristle temperatures with the downstream bristles being hotter. These results clearly demonstrate that conduction in the bristles is an important mechanism in dissipating the frictional heat, but it should be noted that in practice the problem will be further complicated by heat transfer in the rotor, conduction between contacting bristles, and heat transfer and flow in the pack beyond the present computational domain.

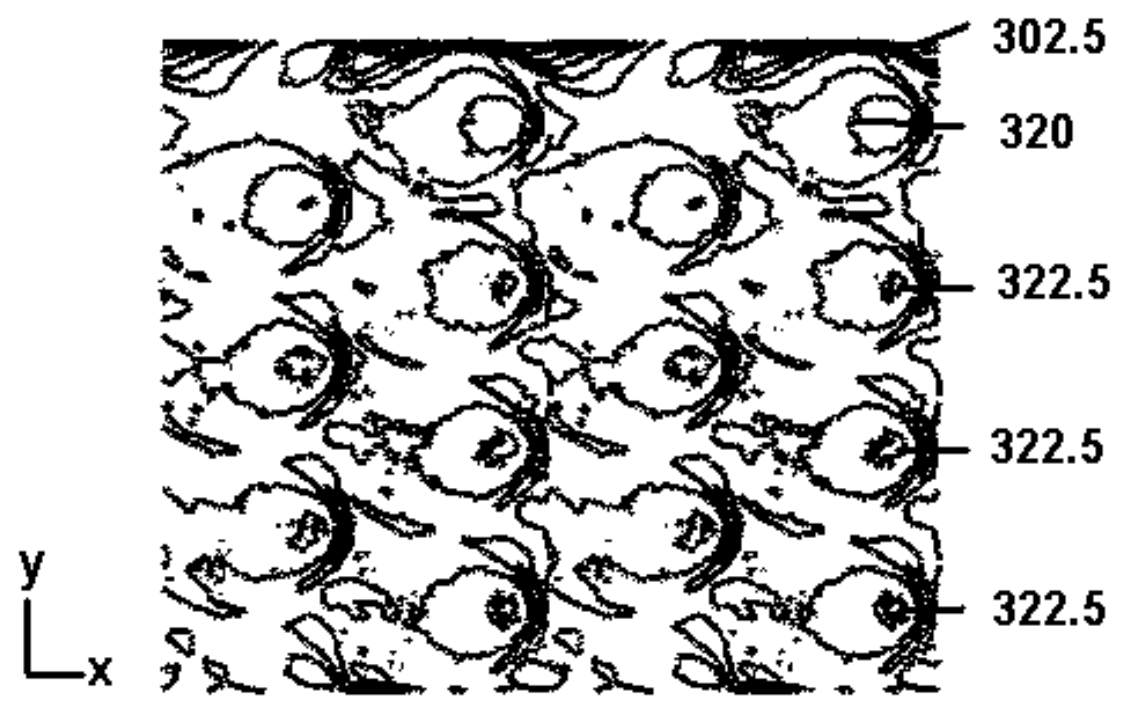

Fig. 15. Temperature contours on rotor for case with heat generation due to solid contact friction and heat conductive bristle tops. $($ Contour interval $=2.5 \mathrm{~K})$

\section{CONCLUSIONS}

New insight has been given into the behaviour of brush seals and CFD has been successfully applied to study flow and heat transfer in such seals. CFD solutions for tip region flows have confirmed that air-riding effects can be significant and support the hypothesis that 'tilting' of the bristle tip as the rotor-to-stator gap changes is important. Further CFD solutions combine flow solutions in the tip region with heat conduction solutions for the bristles. The CFD solutions indicate that the lift is not very sensitive to the packing arrangement of the bristles, the axial pressure gradient, or the generation of heat due to rubbing of the bristles on the rotor. 
The proposed mechanism for aerodynamic lift is consistent with other workers' experimental observations. However, uncertainties remain, and it should be noted that the mechanism has not been clearly demonstrated experimentally in real brush seals. This would require very careful experiments as the lift is very sensitive to the tilt angle and minimum bristle-to-rotor clearance. The lift achieved in practice is likely to be sensitive to surface roughness on both the rotor and bristle tip. Surface roughness is probably a limiting factor on the 'effective' clearance and the level of lift that can be achieved. Surface finish of the rotor is likely to require attention in any development taking advantage of this effect. Large relative movements of the rotor and stator are likely to cause difficulties, as these may shift the tip inclination angle out of the desired range.

\section{ACKNOWLEDGEMENTS}

This work has been sponsored by a University of Surrey foundation grant and in part by Rolls Royce plc. Many interesting and useful discussions of brush seal behaviour with colleagues at Oxford University and Rolls-Royce are also gratefully acknowledged. Discussions with Professor T. Jones and Dr E. Woods have been particularly valuable.

\section{REFERENCES}

Acheson, D. J. ,1990. Elementary Fluid Dynamics, Oxford University Press

Aksit, M. F. and Tichy, J. A., 1996. A computational model of brush seal bristle deflection. Proceedings of 32nd AIAA/ASME/SAE/ASEE Joint Propulsion Conference, 96-2909.

Anderson, J. D., 1989. Hypersonic and High Temperature Gas Dynamics, McGrawHill

Bayley, F. J. and Long, C. A., 1993. A combined experimental and theoretical study of flow and pressure distributions in a brush seal. ASME J. Engng for Gas Turb. and Power115, 404-410.

Chen, L. H., Wood, P. E., Jones, T. V. and Chew, J. W., 1999. An iterative CFD and mechanical brush seal model and comparison with experimental results. ASME J. Engng for Gas Turb. and Power121, 656-662.

Chen, L. H., Wood, P. E., Jones, T. V. and Chew, J. W., 2000. Detailed experimental studies of flow in large scale brush seal model and a comparison with CFD predictions. ASME J. Engng for Gas Turb. and Power 200, 1-7.

Chew, J. W., Lapworth, B. L. and Millener, P. J., 1995. Mathematical modelling of brush seals. Int. J. Heat and Fluid Flow 16 493-500.

Chupp, R. E. and Holle, G. F., 1992. Simple leakage model for brush seals Proceedings of 27th AIAA/SAE/ASME Joint Propulsion Conference, 91-1913.

Fluent Inc. (1998) http:Ilwww.fluent.com 
Guardino, C., Chew, J. W. and Hills, N. J., 2002. Calculation of surface roughness effects on air-riding seals. ASME Turbo Expo paper GT-2002-30246. (Also to appear in ASME J. Engng for Gas Turb. and Power)

Hendricks, R. C., Schlumbergeer, S., Braun, M. J., Choy, F. and Mullen, R. L., 1991. A bulk flow model of a brush seal system. International Gas Turbine \& Aeroengine Congress and Exposition, Orlando, paper 91-GT-325.

Hutchings, I. M., 1992. Tribology - Friction and Wear of Engineering Materials. Edward Arnold, UK.

Wood, P. E., 1997. Brush seal dynamics tests, report no. 5, University of Oxford. 